\title{
The Impact of Integrated Financial Management Information Systems on Procurement Process in Public Sector in Developing Countries-A Case of Zambia
}

\author{
Timothy Muwema1, Jackson Phiri² \\ ${ }^{1}$ Graduate School of Business, University of Zambia, Lusaka, Zambia \\ ${ }^{2}$ School of Natural Sciences, Department of Computer Sciences, University of Zambia, Lusaka, Zambia \\ Email: timothymuwema@yahoo.com, jackson.phiri@cs.unza.zm
}

How to cite this paper: Muwema, T. and Phiri, J. (2020) The Impact of Integrated Financial Management Information Systems on Procurement Process in Public Sector in Developing Countries-A Case of Zambia. Open Journal of Business and Management, 8, 983-996.

https://doi.org/10.4236/ojbm.2020.82062

Received: May 24, 2019

Accepted: March 28, 2020

Published: March 31, 2020

Copyright $\odot 2020$ by author(s) and Scientific Research Publishing Inc. This work is licensed under the Creative Commons Attribution International License (CC BY 4.0).

http://creativecommons.org/licenses/by/4.0/

cc) (i) Open Access

\begin{abstract}
Progressive governments around the world aim at having efficient Public Finance Management in order to efficiently manage resources and maximize opportunity costs associated with Public Procurement. The Government of Zambia has introduced Integrated Financial Management Information Systems (IFMIS) to monitor how ministries, departments and other state agencies spend funds on a real-time basis in order to improve budget implementation. The objectives of IFMIS are to attain transparency, reduce financial leakages and accountability in the way Government resources are being spent. Data were collected from seventy-five (75) respondents from the Ministry of Finance, Ministry of Works and Supply and the Anti-Corruption Commission. Data were analysed using Social Package and Social Sciences (SPSS) version 20 and Microsoft Excel. The study revealed that there is a significant negative relationship between IFMIS and transparency, reduced financial leakages and efficiency and speed. The study thus concluded that IFMIS has not enhanced transparency, reduced financial leakages, enhanced efficiency and speed. The study recommended that vendors and citizens should have access to the system to enhance transparency. Furthermore, the study recommended for code restructuring of the system to make it more proactive rather than reactive in order to improve budget adherence, reduce misappropriation and misapplication of funds. In conclusion, the study further recommended procurement processes be carried on the system only and eliminate the duplication of work on paper.
\end{abstract}

\section{Keywords}

Integrated Financial Management Information Systems (IFMIS), Procurement 
Process, Public Sector

\section{Introduction}

The Government of Zambia has introduced IFMIS to monitor how ministries, departments and other state agencies spend funds on a real-time basis in order to improve budget implementation. The objectives of IFMIS are to attain transparency, reduce financial leakages and accountability in the way Government resources are being spent. The Government of Zambia has introduced IFMIS to monitor how ministries, departments and other state agencies spend funds on a real-time basis in order to improve budget implementation. The objectives of IFMIS are to attain transparency, reduce financial leakages and accountability in the way Government resources are being spent [1].

The fragmented systems of handling government finances have always been too expensive for the taxpayers. The Government of Zambia through Ministry of Finance has introduced IFMIS in order to enhance transparency, reduce financial leakages and enhance accountability [1]. This research thus seeks to find out how the implementation of IFMIS has impacted public procurement in promoting transparency, efficiency, speed, less financial leakages as a means of paying vendors/customers on behalf of ministries, departments and other state agencies.

The study is significant because it will act as an advocacy to the Ministry of Finance and National Planning on the impact of IFMIS on the procurement processes in public procurement; this will enable the ministry to enhance the implementation of IFMIS and enable the system to meet the desired objectives by making the necessary improvements that will be recommended.

\section{Literature Review}

An IFMIS is a standardized monitoring and reporting system, which consolidates all the information needs of a government into one information database. It facilitates consistent recording and reporting of information, to enable a government to take macro decisions that affect the country [2]. In the government realm, IFMIS systems must be designed to support distinctly public sector functions. They must be able to handle and communicate all the financial movements for the complex structure of budget organizations [3]. In Rwanda, IFMIS was built and suited to the needs of the Rwandan government and that has resulted to the system yielding the intended purposes [4].

According to [5] who conducted a study on TSA and IFMIS, the study revealed that TSA and IFMIS system requires political will, honesty and determination so as to overcome the various challenges identified in the paper in order to liberate the full benefits of the system. World Bank study revealed that many countries do not publish financial data to their citizens extensively, thus have not used systems such as IFMIS to publish data [6]. However, other studies have re- 
vealed that there is significant contribution of IFMIS on performance of public institutions in Rwanda [4]. Literature postulates that Code restructuring can be used to enhance quality of IFMIS outcome [4].

The reviewed literature shows that IFMIS has been in implementation in Zambia for quite some time. The literature further shows that using e-procurement or systems that digitize procurement can enhance transparency, effectiveness and efficiency, speed and reduce financial leakages in public procurement. However, there has not been any study done to investigate the Impact of IFMIS on procurement processes in public sector in Zambia. It is this gap in literature that this study is trying to fill in.

\subsection{Source of the Model of This Research}

The research reviewed a lot of theories and models done by other researchers in line with the research topic in order to have an in depth understanding and be able to develop a model that will provide a solution to the problem of research. The following theories were reviewed; Software Restructuring Model and Technology Acceptance Model.

\subsubsection{Software Restructuring Model}

Software restructuring model focuses on inventory analysis, document restructuring, reverse engineering, code reengineering, data restructuring and forward engineering [7]. It provides abstracted design information derived from program code and the module interface information needed for restructuring.

IFMIS has a number of components and modules that aid in its operations. These modules include; procurement module, accounts payable module, accounts receivable module, tax module, cash management module, budget planning module and transactions module. Code restructuring can be done around the modules to enhance delivery outcomes of the system [8].

In this study, the model was used to enhance understanding of IFMIS reengineering and how code reengineering can be used to yield positive impact of IFMIS on public procurement processes.

The model is presented in Figure 1.

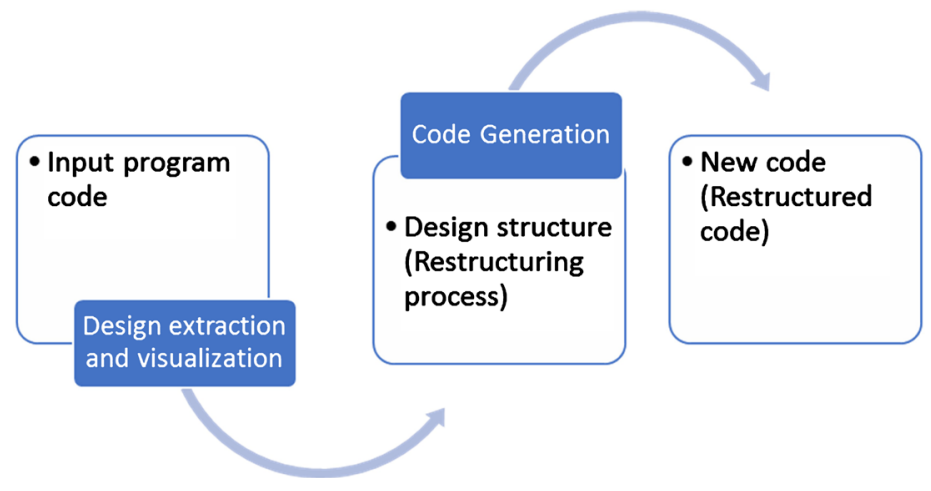

Source, Micheni (2016).

Figure 1. Code restructuring model. 
Furthermore, software restructuring model was used to conceptualize software code restructuring and potential outcome on the impact of IFMIS on public procurement processes. IFMIS system is designed to connect, accumulate, process, and provide information to all intended parties on a continuous basis.

\subsubsection{Technology Acceptance Model}

The Technology Acceptance Model (TAM) suggests that there are a number of factors determine the decision about how to adopt and use a new technology [9]. The theory proposes a relationship between users' acceptance of a new information system and the users' perceptions of the ease of use and usefulness of the information system [10]. The theory proposes that adoption of new technology requires integration of the external factors and internal organizational factors such as; perceives usefulness of the system, perceived ease of use, attitude towards use of the system, behavioral intention behind adoption and use and the actual systems' use [11].

User acceptance of a new technology is based on the influence of perceived usefulness and perceived ease of use of the system [9]. The model explains that user perceptions of usefulness and ease of use determine attitudes toward using the system are influencers of acceptance. Behavioral intentions to use are determined by users' attitudes toward using the system. Behavioral intentions to use the system then determine actual system use. The model provides a direct link between perceived usefulness and behavioral intentions to use (Figure 2).

In this study, the model provides an insight on how personal factors could influence the impact of IFMIS on procurement processes in public sector. IFMIS use in public procurement in the public sector involves people literally at all stages. From the perceived link between personal factors and impact of IFMIS on procurement processes, government policy makers need to make rational decisions that enhance people participation and consequently yield the desired benefits of IFMIS that can enhance transparency, enhance efficiency and speed and reduce financial leakages [5].

\subsection{IFMIS Impact on Procurement Processes Model}

The model that was used in this research was a prescriptive research model.

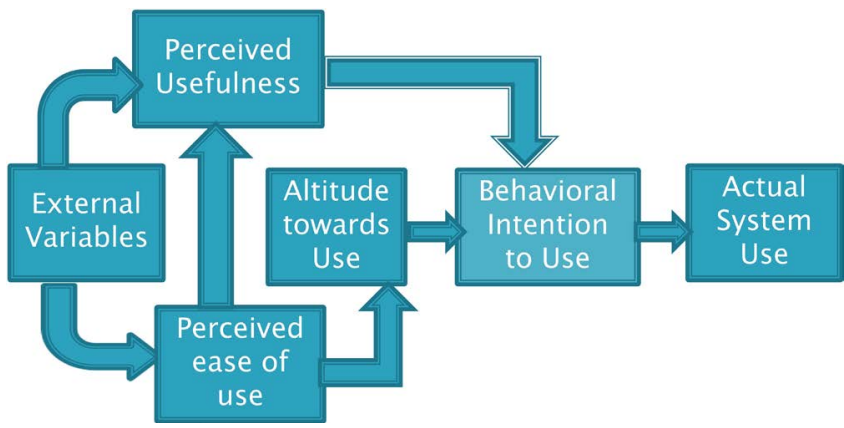

Source (Soneka and Phiri, 2019)

Figure 2. Technology acceptance model. 
According to [11] prescriptive models are representations which along with identifying dependent and independent variables, focus on the understanding of the explicit and implicit relationships among these variables. Under prescriptive model, the specific research model that was used in this dissertation was Multi-Tier Influence model. Multi-tier influence model is an extension of simple influence model involving multiple levels. Level 1 consists of independent variables; the last level has the final dependent variables and other levels contain intermediate variables.

As can be seen below, the model has dependent variable (IFMIS) and independent variables (transparency, financial leakage, efficiency and speed). Correlation and multiple regression statistics was used to determine the relationship between independent and dependent variables and thus be able to make conclusions and recommendations inclined on the model below (Figure 3).

This journal aims to use this model to solve the problem identified as outlined on the problem statement and the introduction.

\section{Methodology}

The research design that was used was descriptive survey. Descriptive research is done with a specific research question in mind. It gives a set view of the subject, population, market segment or problem. Descriptive research provides research questions, populations or methods of analysis before the research is started.

The target population for this research was the Ministry of Finance Headquarters, Works and supply and the Anti-Corruption Commission. The study included the staff that was in charge of IFMIS and the procurement and supplies

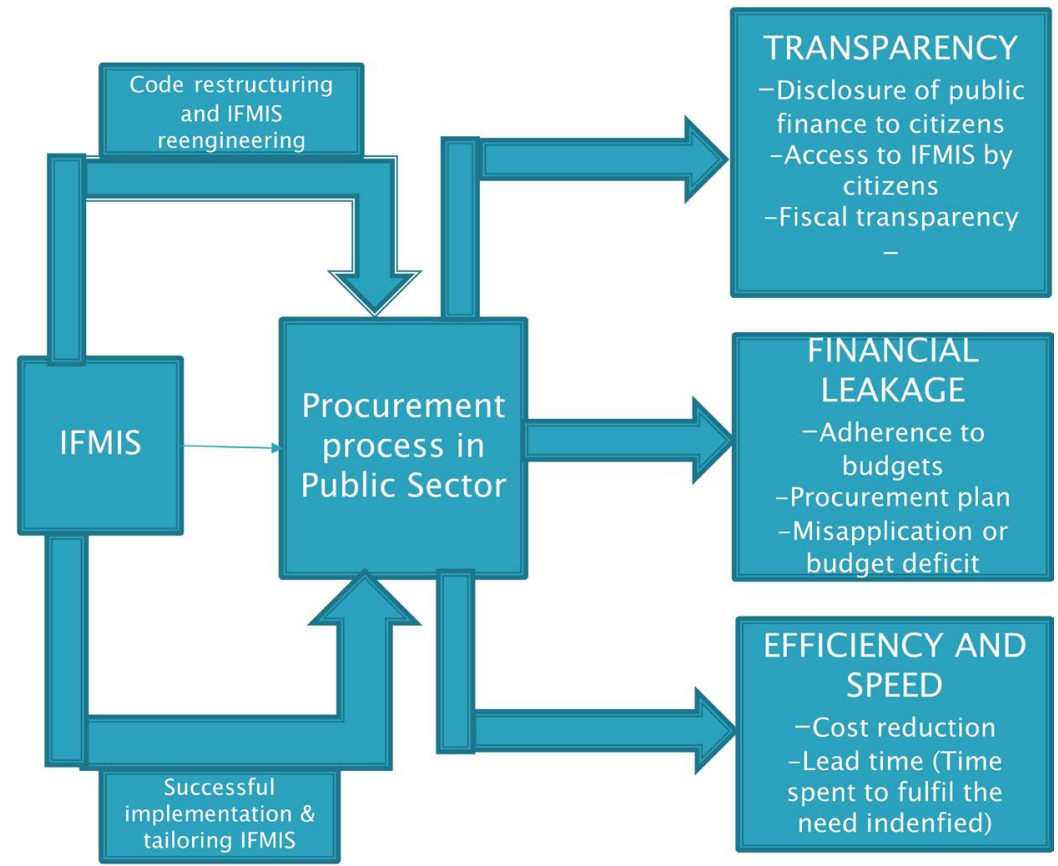

Source: Author (2019).

Figure 3. Model of the research. 
department at the Ministry of Finance, also the staff in procurement and supplies unit and finance unit at the Anti-Corruption Commission and Ministry of Works and supply.

Members of staff who work in other departments other than procurement and finance units at ACC, Ministry of works and supply did not participate in the study. Furthermore, members of staff who were not in the IFMIS department and Procurement department at the Ministry of Finance did not participate in the study.

The researcher adopted a sample size using purposive sampling method. Yamane's formula [12] coined by Yamane, 1967.

$$
n=\frac{N}{\left[1+N\left(e^{2}\right)\right]}
$$

Eighty (80) respondents were adequate representation of the population to represent the staff from the Ministry of Finance and the Anti-Corruption Commission.

The researcher used questionnaires and interviews to collect primary data. Secondary data was collected from peer reviewed publications such as journals, and conference proceedings.

The Microsoft Excel and Statistical Package for Social Sciences (SPSS) version 20 was used to analyze the data. The specific statistical method that was used was descriptive statistics from SPSS version 20.

\section{Results}

Table 1 below highlights the Pearson Correlation and P-values for the variables used in this research; IFMIS and transparency, financial leakages, efficiency and speed. In statistics, the correlation coefficient $r$ measures the strength and direction

Table 1. Summary output for Pearson correlation coefficients and p-values.

\begin{tabular}{|c|c|c|c|c|c|c|c|c|}
\hline \multicolumn{9}{|c|}{ SUMMARY OUTPUT FOR PEARSON CORRELLATION COEFFICIENTS AND P-VALUES } \\
\hline \multicolumn{9}{|c|}{ Regression Statistics } \\
\hline Multiple R & -0.690 & & & & & & & \\
\hline R Square & -0.477 & & & & & & & \\
\hline Adjusted R Square & -0.455 & & & & & & & \\
\hline Standard Error & 0.962 & & & & & & & \\
\hline Observations & 75 & & & & & & & \\
\hline \multicolumn{9}{|l|}{ ANOVA } \\
\hline & $d f$ & SS & MS & $F$ & Significance $F$ & & & \\
\hline Regression & 3.00000 & 59.91767 & 19.97256 & 21.56328 & 0.0000000 & & & \\
\hline Residual & 71.00000 & 65.76233 & 0.92623 & & & & & \\
\hline \multirow[t]{2}{*}{ Total } & 74.00000 & 125.68000 & & & & & & \\
\hline & Coefficients & Standard Error & $t$ Stat & P-value & Lower 95\% & Upper 95\% & Lower $95.0 \%$ & Upper $95.0 \%$ \\
\hline Intercept & 0.567 & 0.299 & 1.895 & 0.062 & -0.030 & 1.163 & -0.030 & 1.163 \\
\hline Transparency & -0.320 & 0.150 & -2.134 & 0.036 & -0.618 & -0.021 & -0.618 & -0.021 \\
\hline Financial Leakage & -0.356 & 0.111 & -6.825 & 0.000 & -0.538 & -0.094 & 0.538 & 0.983 \\
\hline Efficiency and Speed & -0.356 & 0.119 & -2.624 & 0.011 & -0.075 & -0.548 & 0.075 & 0.548 \\
\hline
\end{tabular}

Source, Author (2019). 
of a linear relationship between variables on a scatterplot. The value of $r$ is always between +1 and -1 .

Table 1 shows the correlation Coefficient. From this Table 1, it shows that the correlation coefficient $(\mathrm{r})$ is $-0.690(\mathrm{r}=-0.690)$ which indicates a strong negative statistical relationship between IFMIS and transparency, financial leakages, efficiency and speed because it is closer to -1 (Table 1 ).

\subsection{Statistical Significance (P-Values)}

A small P-Value of 0.00000001 as can be seen on the figure above provides strong evidence to reject the null hypothesis. From this study we are able to see that the $\mathrm{P}$-value is 0.0000001 is less than $(\mathrm{P} \leq 0.05)$ as shown in Figure 4 which indicates a significant negative statistical relationship between IFMIS and transparency, financial leakages and efficiency and speed. Therefore, the alternative hypothesis is maintained that there is a significant relationship between IFMIS and transparency, financial leakages and efficiency and speed.

\subsection{IFMIS and Transparency}

One of the objectives of IFMIS was to enhance transparency of financial information that is shared to the citizens of Zambia in order to keep government accountable. Under objective one of this research, part of it was to determine if IFMIS has enhanced transparency on the procurement processes carried out in the public sector.

The study findings reveal that citizens have no access to the system and financial information with regards to certain procurements that are being carried by different ministries and spending agencies. As the result citizens are still not able to keep government accountable because they have no access to the information that is on IFMIS. This finding reveals that IFMIS has not meant its objective of

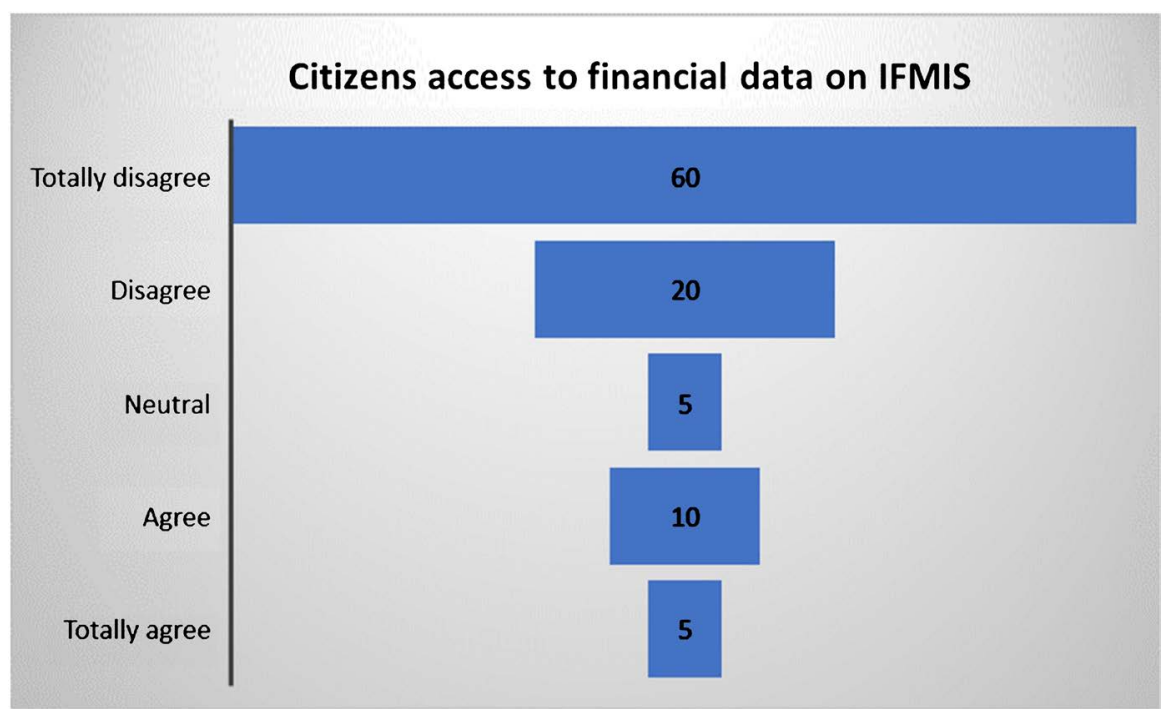

Source: Author (2019).

Figure 4. Citizens access to financial data on IFMIS. 
enhancing transparency of ensuring that citizens have access to financial information. According to [2] IFMIS project can enhance transparency which in turn supports better governance and decision making. The findings of this study are not in agreement with what [2] postulated. The figure below shows responses on citizens access to financial data on IFMIS.

Furthermore, the study findings revealed that vendors have NO access to IFMIS system. This was one of the major indicators that procurement processes are being carried outside the system and IFMIS is just being loaded with the already done procurement outside the system. According to [6] Fiscal transparency can improve trust in government, if the public interpret the motives for publishing the Open Budget Data positively, and the transparency is maintained for long periods, benefiting from reliable IFMIS solutions. Figure 5 shows responses on vendors access to IFMIS.

\subsection{IFMIS and Financial Leakage}

The study further had to determine if IFMIS has reduced financial leakages on the procurement of goods and services in the public sector. The foundation of this comes from the problem statement where the study noted a lot of misapplication of funds, misappropriation of funds captured in the auditor general's report of the financial year of 2017 and news on the procurements which have not shown value for money such as the fire tenders and ambulances under the ministry of local government and the ministry of health.

The study findings reveal that majority of the respondents disagreed that IFMIS has reduced financial leakages because the actual procurement processes are conducted outside the system and are only loaded afterwards. This finding was in agreement with [13] what argued that accounting systems mainly reciprocated the manual processes. On the other hand, to those who agreed that IFMIS has reduced financial leakages they indicated that the scandals of financial leakages are less as compared to the previous number of scandals that were captured before many ministries were on the system. Figure 6 shows responses on IFMIS reducing financial leakages in public procurement.

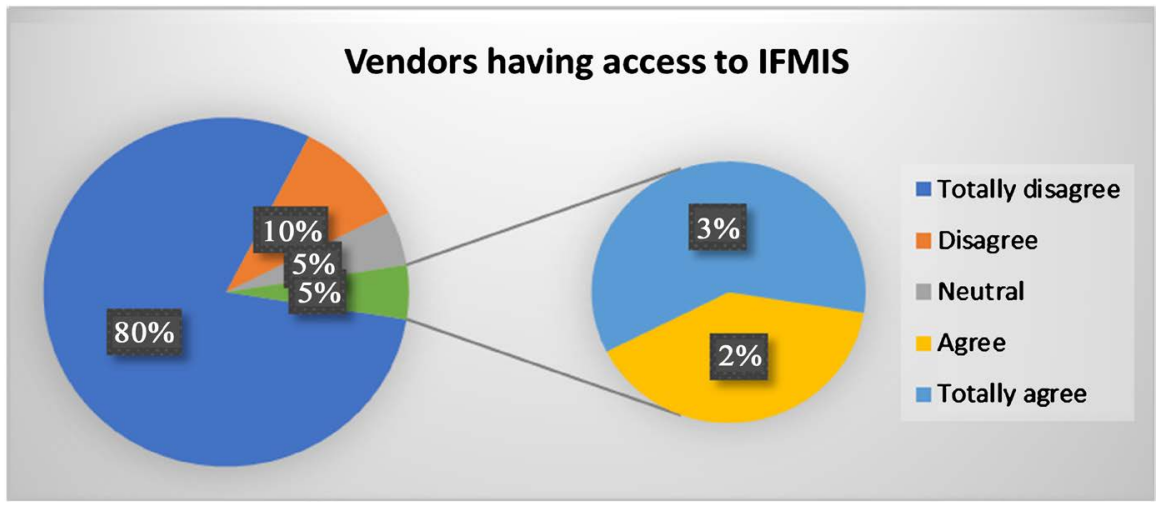

Source, Author (2019).

Figure 5. IFMIS and financial leakage. 
The study findings reveal that majority of the respondents indicated that IFMIS has not reduced misapplication of funds because controlling officers are still able to vary the funding to other issues which they see to be important rather than sticking to the budget. One of the objectives of IFMIS was to enhance budget adherence by funding the budget lines according to the profiles and expect that the money should be used according to the budget. The figure below shows responses on IFMIS reducing misapplication of funds by budget holders.

\subsection{IFMIS and Efficiency and Speed}

The study had to find out if IFMIS has enhanced efficiency and speed in the way procurement processes are being carried out presently. Efficiency had to determine the cost aspect of procurement processes, on the other hand, speed had to determine the lead time procurement processes are taking from need identification and initiation to the point when the need is fulfilled.

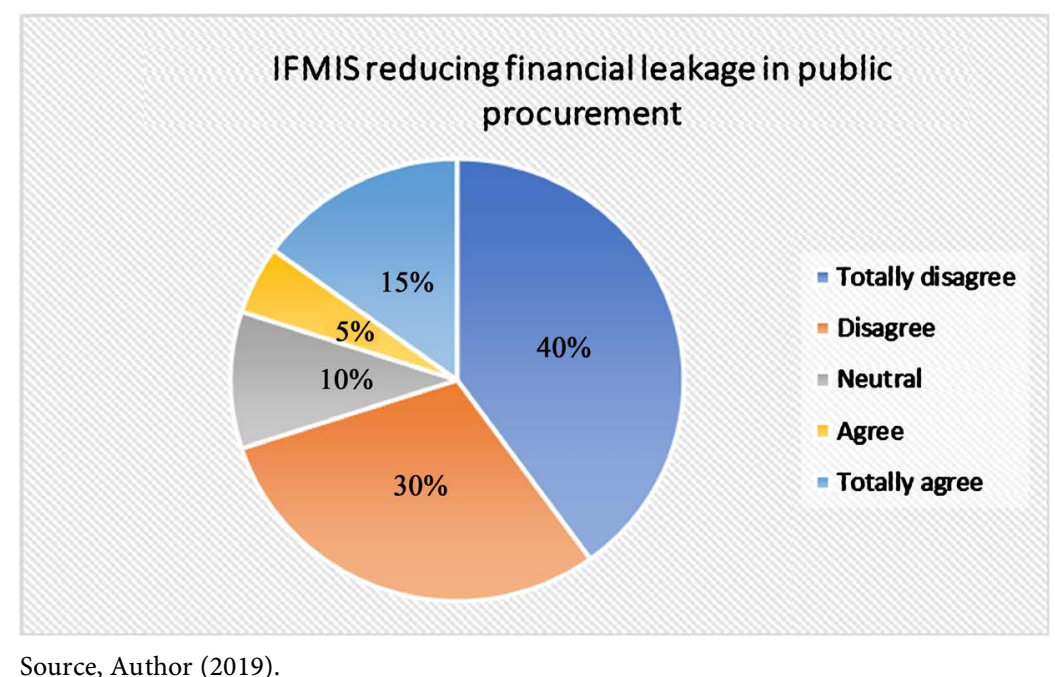

Figure 6. IFMIS reducing financial leakage in public procurement.

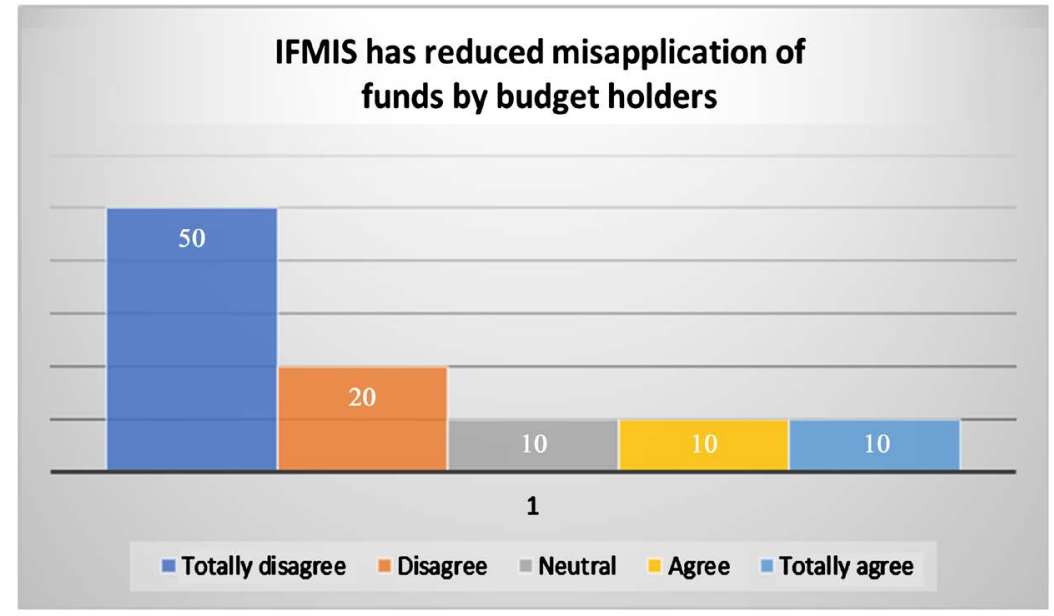

Source, Author (2019).

Figure 7. IFMIS has reduced misapplication of funds by budget holders. 
The study findings reveal that majority of the findings totally disagreed that IFMIS has enhanced efficiency in carrying out procurement processes. The findings reveal that IFMIS has doubled the work and the cost of carrying out procurement processes because work is being done twice on hard copies and also on the system. The study further reveals that many players have also been added on IFMIS procurement processes in order to have a good number of authorities approve the procurement being carried out. Many basic functions such as loading a vendor on the system have been centralised by the Ministry of Finance through the IFMIS department with insufficient capacity. According to [3] Public Service Reform Programme (PSRP) was being implemented by government to improve efficiency and effectiveness of public service delivery. The findings of this study on IFMIS and efficiency are not in agreement with what White and Lawrence postulated. Figure 8 shows responses on IFMIS enhancing efficiency in procurement processes.

The study findings indicate that IFMIS has not increased speed in procurement processes. The study findings further reveal that IFMIS has not increased any speed in the procurement processes because work has tripled, more people are delaying flow of work and many functions have centralised by Ministry of Finance with inadequate capacity. Furthermore, the study revealed that IFMIS has no room for emergency procurements thus delaying even the emergency procurements that are urgently needed. The figure below shows responses on IFMIS increasing speed in the procurement processes.

\section{Discussions}

The study findings revealed that vendors and citizens have no access to the system and access financial information with regards to certain procurements that are being carried by different ministries and spending agencies. As the result citizens are still not able to keep government accountable because they have no access to the information that is on IFMIS. This finding reveals that IFMIS has not meant its objective of enhancing transparency of ensuring that citizens have

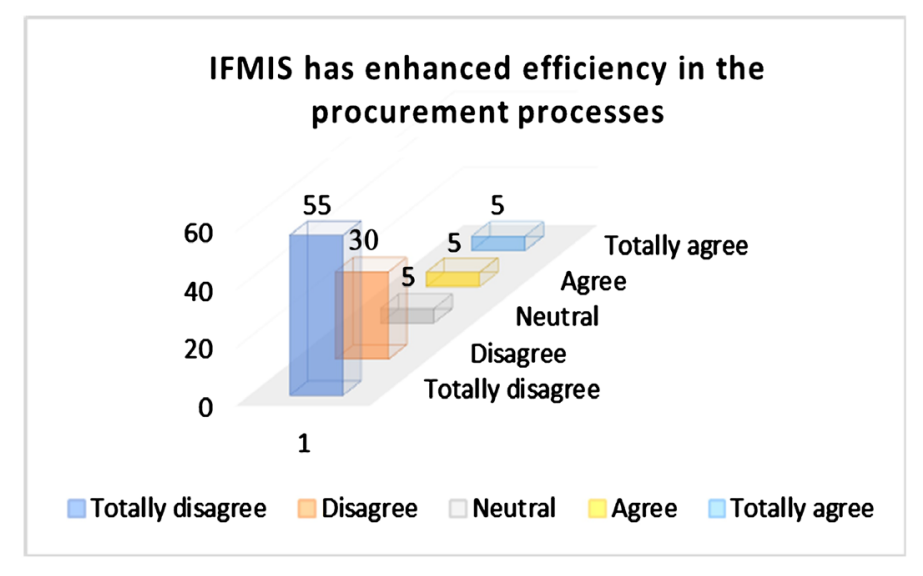

Source: Author (2019).

Figure 8. IFMIS has enhanced efficiency in the procurement processes. 


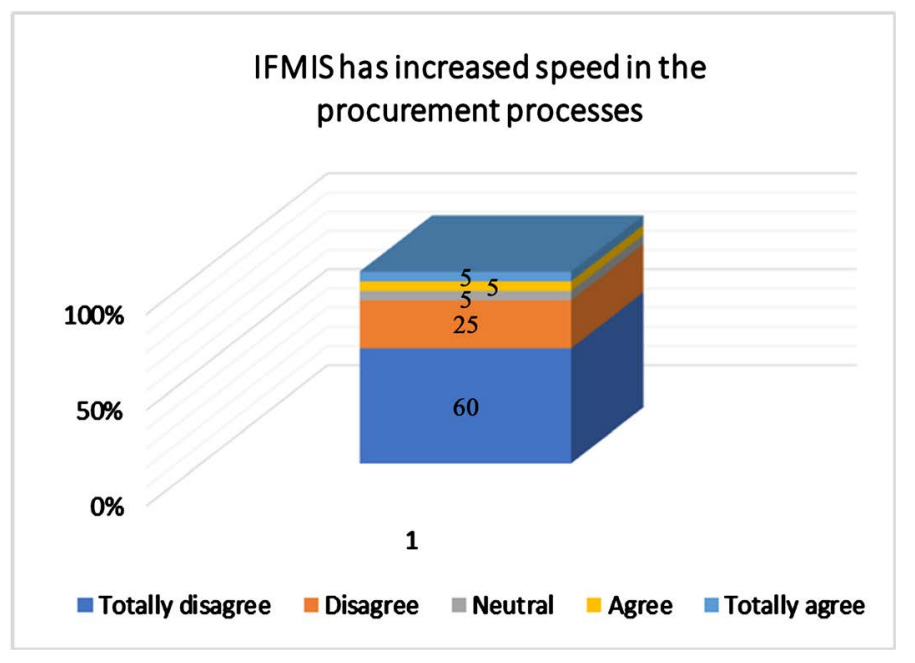

Source: Author (2019).

Figure 9. IFMIS has increased speed in procurement processes.

access to financial information. According to [14] IFMIS project can enhance transparency which in turn supports better governance and decision making. The findings of this study are not in agreement of with what [4] postulated. According to [6] Fiscal transparency can improve trust in government, if the public interpret the motives for publishing the Open Budget Data positively, and the transparency is maintained for long periods, benefiting from reliable IFMIS solutions.

The study findings revealed that majority of the respondents disagreed that IFMIS has reduced financial leakages because the actual procurement processes are conducted outside the system and are only loaded afterwards. This finding was in agreement with what [5] argued that accounting systems mainly reciprocated the manual processes. On the other hand, to those who agreed that IFMIS has reduced financial leakages they indicated that the scandals of financial leakages are less as compared to the previous number of scandals that were captured before many ministries were on the system. The study findings reveal that majority of the respondents indicated that IFMIS has not reduced misapplication of funds because controlling officers are still able to vary the funding to other issues which they see to be important rather than sticking to the budget. One of the objectives of IFMIS was to enhance budget adherence by funding the budget lines according to the profiles and expect that the money should be used according to the budget.

The study findings reveal that majority of the findings totally disagreed that IFMIS has enhanced efficiency in carrying out procurement processes. The findings reveal that IFMIS has doubled the work and the cost of carrying out procurement processes because work is being done twice on hard copies and also on the system. The study further reveals that many players have also been added on IFMIS procurement processes in order to have a good number of authorities approve the procurement being carried out. Many basic functions such 
as loading a vendor on the system have been centralised by the Ministry of Finance through the IFMIS department with insufficient capacity. According to [7], Public Service Reform Programme (PSRP) was being implemented by government to improve efficiency and effectiveness of public service delivery. The findings of this study on IFMIS and efficiency are not in agreement with what White and Lawrence postulated.

The study findings indicate that IFMIS has not increased speed in procurement processes. The study findings further reveal that IFMIS has not increased any speed in the procurement processes because work has tripled, more people are delaying flow of work and many functions have centralised by Ministry of Finance with inadequate capacity. Furthermore, the study revealed that IFMIS has no room for emergency procurements thus delaying even the emergency procurements that are urgently needed.

\section{Conclusion}

The study thus concluded that IFMIS has not enhanced transparency in procurement processes carried out in public sector because citizens and vendors have no access to the system as such the information that is on the system is not open and accessible to them. As a result, citizens are still not able to keep government accountable because they have no access to the information that is on IFMIS. Vendors have no access to IFMIS because procurement processes are being carried outside the system and IFMIS is just being loaded with the already done procurement outside the system. This is evident as can be seen from Figure 4 and Figure 5 above. One of the objectives of IFMIS was to enhance budget adherence by funding the budget lines according to the profiles and expect that the money should be used according to the budget and this is not being achieved currently. This is evident as can be seen from Figure 7 above. The study further reveals that IFMIS has not increased speed in procurement processes because work has tripled, more people are delaying flow of work and many functions have been centralised by Ministry of Finance with inadequate capacity. Furthermore, the system has no room for emergency procurements thus delaying even the emergency procurements that are urgently needed. This is evident from Figure 9 above in the findings and discussions.

\section{Recommendations}

Citizens should have access to the system in order to make government accountable for the works, goods and services government is procuring. For example, if citizens are aware of the cost of certain projects, the start and the completion period in relation to the payments, many projects would have been completed on time because citizens would have been whistle blowers on projects where vendors have been paid without completing the works relative to the payment. This recommendation was inclined on findings that revealed that vendors and citizens have no access to IFMIS as can be shown in Figure 5 above. IFMIS system 
should undergo code restructuring to enable it to enforce budget adherence thus reducing misappropriation and misapplication of funds. IFMIS should not be used as a tool for reporting or loading fraudulent type of procurements, the system should be proactive and not reactive to detect fraud and manipulation before it happens. Code restructuring should be coupled with strong human enforcement to ensure that the users follow the laid down guidelines by the system without breaking them. This recommendation emanates from the findings as can be seen from Figure 4 and Figure 7 that shows that IFMIS has not reduced financial leakages. Pearson correlation and multiple regression in Figure 4 shows a strong negative relationship between the independent and dependent variable thus making this recommendation.

\section{Future Research}

The study proposes that an assessment on the impact of code restructuring and implementation of information management systems in developing countries.

\section{Acknowledgments}

I wish to acknowledge the staff from the Ministry of Finance and the Anti-Corruption Commission who took part in the study.

\section{Conflicts of Interest}

The authors declare no conflicts of interest regarding the publication of this paper.

\section{References}

[1] Chitundu, N. (2006) IFMIS Presentation to World Bank by Ministry of Finance and National Planning, Lusaka, Zambia.

[2] Martin, C. (2015) Logistics and Supply Chain Management. 2nd Edition, FT Prentice Hall, London.

[3] Manning, N., Shepherd, G. and Guerrero, A. (2010) Why Trust in Government Matters? Chapter 2 of Results, Performance Budgeting and Trust in Government. World Bank, Washington DC.

[4] Harelimana (2017) Impact of Integrated Financial Management Information System on Performance of Public Institutions in Rwanda. Macro Think Institute Publishers, Las Vegas. https://doi.org/10.5296/erm.v3i1.12230

[5] Isa, A.A. (2016) The Treasury Single Account (TSA) as an Instrument of Financial Prudence and Management: Prospects and Problems. Research Journal of Finance and Accounting, 7, 66-71.

[6] World Bank FMIS Database (1984-2013).

[7] Micheni, E (2016) Adoption of Code Restructuring to Enhance Full Cycle End-to-End Integrated Financial Management Information System in the Public Sector in Kenya: A Review Paper. American Journal of Networks and Communications, 5, 139-145. https://doi.org/10.11648/j.ajnc.20160506.13

[8] Dener, C., Watkins, J.A. and Dorotinsky, W.L. (2011) Financial Management Information Systems: 25 Years of World Bank Experience on What Works and What 
Doesn't. World Bank Study. World Bank, Washington DC. https://doi.org/10.1596/978-0-8213-8750-4

[9] Soneka, P.N. and Phiri, J. (2019) A Model for Improving E-Tax Systems Adoption in Rural Zambia Based on the TAM Model. Open Journal of Business and Management, 7, 908-918. https://doi.org/10.4236/ojbm.2019.72062

[10] Stannack, P. (2009) Purchasing Power and Supply Chain Management Power-Two Different Paradigms? A Response to Ramsay's 'Purchasing Power' (1995). European Journal of Purchasing \& Supply Management, 2, 47-56. https://doi.org/10.1016/0969-7012(95)00021-6

[11] Amaratunga, D. and Baldry, D. (2012) Moving from Performance Measurement to Performance Management. Facilities, 20, 217-223.

https://doi.org/10.1108/02632770210426701

[12] Slack, C. and Johnston, R. (2016) Operations Research. 3rd Edition, Pearson Education Limited, London.

[13] Waters, D. (2015) Operations Management. Pearson Education Limited, Britain.

[14] Biemba, G., Chiluba, B., Yeboah-Antwi, K., Silavwe, V., Lunze, K., Mwale, R.K., Russpatrick, S. and Hamer, D.H. (2018) Implementing Financial Management Information Systems in Local Governments: A Model of Success Factors.

https://www.scopus.com/inward/record.uri?eid=2-s2.0-85051179089\&partnerID=4 $\underline{0 \& m d 5=2 f 913885851 \mathrm{ffe} 94988 \mathrm{ac} 219205 \mathrm{bde} d \mathrm{~d}}$ 